\title{
Modafinil improves methamphetamine-induced object recognition deficits and restores prefrontal cortex ERK signaling in mice
}

\author{
Betina Gonzalez ${ }^{1}$, Mariana Raineri ${ }^{1}$, Jean Lud Cadet ${ }^{3}$, Edgar García-Rill ${ }^{4}$, Francisco J. \\ Urbano $^{2}$, and Veronica Bisagno ${ }^{1, \#}$ \\ ${ }^{1}$ Instituto de Investigaciones Farmacológicas (Universidad de Buenos Aires - Consejo Nacional \\ de Investigaciones Científicas y Técnicas), Ciudad Autónoma de Buenos Aires, Buenos Aires, \\ Argentina \\ ²Laboratorio de Fisiología y Biología Molecular, Instituto de Fisiología, Biología Molecular y \\ Neurociencias (Universidad de Buenos Aires - Consejo Nacional de Investigaciones Científicas y \\ Técnicas), Ciudad Autónoma de Buenos Aires, Buenos Aires, Argentina \\ ${ }^{3}$ Molecular Neuropsychiatry Research Branch, NIH/NIDA Intramural Research Program, \\ Baltimore, Maryland, United States of America \\ ${ }^{4}$ Center for Translational Neuroscience, Department of Neurobiology and Developmental \\ Sciences, University of Arkansas for Medical Sciences, Little Rock, Arkansas, United States of \\ America
}

\section{Abstract}

Chronic use of methamphetamine (METH) leads to long-lasting cognitive dysfunction in humans and in animal models. Modafinil is a wake-promoting compound approved for the treatment of sleeping disorders. It is also prescribed off label to treat METH dependence. In the present study, we investigated whether modafinil could improve cognitive deficits induced by sub-chronic METH treatment in mice by measuring visual retention in a Novel Object Recognition (NOR) task. After sub-chronic METH treatment $(1 \mathrm{mg} / \mathrm{Kg}$, once a day for 7 days), mice performed the NOR task, which consisted of habituation to the object recognition arena (5 min a day, 3 consecutive days), training session ( 2 equal objects, 10 min, day 4), and a retention session (1 novel object, $5 \mathrm{~min}$, day 5 ). One hour before the training session, mice were given a single dose of modafinil (30 or $90 \mathrm{mg} / \mathrm{Kg}$ ). METH-treated mice showed impairments in visual memory retention, evidenced by equal preference of familiar and novel objects during the retention session. The lower dose of modafinil $(30 \mathrm{mg} / \mathrm{Kg}$ ) had no effect on visual retention scores in METH-treated mice, while the higher dose $(90 \mathrm{mg} / \mathrm{Kg})$ rescued visual memory retention to control values. We also measured ERK phosphorylation in medial prefrontal cortex (mPFC), hippocampus, and

\footnotetext{
\#Corresponding author: Dr. Veronica Bisagno. Instituto de Investigaciones Farmacológicas (ININFA-UBA-CONICET), Junín 956, piso 5, C1113-Buenos Aires, Argentina. Phone: (+54- 11) 4961-6784, (+54-11) 4963-8593. vbisagno@ffyb.uba.ar.

Publisher's Disclaimer: This is a PDF file of an unedited manuscript that has been accepted for publication. As a service to our customers we are providing this early version of the manuscript. The manuscript will undergo copyediting, typesetting, and review of the resulting proof before it is published in its final citable form. Please note that during the production process errors may be discovered which could affect the content, and all legal disclaimers that apply to the journal pertain.
} 
nucleus accumbens (NAc) of METH- and vehicle-treated mice that received modafinil $1 \mathrm{hr}$ before exposure to novel objects in the training session, compared to mice placed in the arena without objects. Elevated Extracellular signal-regulated kinase (ERK) phosphorylation was found in the mPFC of vehicle-treated mice, but not in METH-treated mice, exposed to objects ( $p<0.05)$. The lower dose of modafinil had no effect on ERK phosphorylation in METH-treated mice, while 90 $\mathrm{mg} / \mathrm{Kg}$ modafinil treatment restored the ERK phosphorylation induced by novelty in METHtreated mice to values comparable to controls $(\mathrm{p}<0.05)$. We found neither a novelty nor treatment effect on ERK phosphorylation in hippocampus or nucleus accumbens (NAc) of vehicle- and METH-treated mice receiving acute $90 \mathrm{mg} / \mathrm{Kg}$ modafinil treatment. Our results showed a palliative role of modafinil against METH-induced visual cognitive impairments, possibly by normalizing ERK signaling pathways in mPFC. Modafinil may be a valuable pharmacological tool for the treatment of cognitive deficits observed in human METH abusers as well as in other neuropsychiatric conditions.

\section{Keywords}

modafinil; methamphetamine; novelty; ERK; prefrontal cortex

\section{INTRODUCTION}

Methamphetamine (METH) is a psychostimulant with a high potential for abuse and addiction. Repeated exposure to METH causes abnormal changes in neurotransmitter activity involved in learning, reward, and executive function (Bamford et al., 2008; Feltenstein and See, 2008). METH also alters neuronal plasticity in brain regions that mediate cognition and motivation (Kauer and Malenka, 2007; Robinson and Kolb, 2004). METH addiction generally begins with recreational use and progresses over time into a compulsive and chronically relapsing disorder, accompanied by psychiatric symptoms including hallucinations and delusions, as well as long-term cognitive deficits (Scott et al., 2007). METH-dependent individuals exhibit high rates of cognitive dysfunction in several neuropsychological domains that include sustained attention, episodic memory, information processing, and impulse control (Monterosso et al., 2005; Nordahl et al., 2003; Simon et al., 2010; Morgan et al., 2012). These cognitive deficits might undermine efforts by METH addicts to stop or reduce METH use and negatively affect the outcome of treatment (Vocci and Appel, 2007). Given the potential links between cognition and treatment outcome in METH dependence, therapeutic approaches that improve cognitive function may be quite promising in the management of METH addiction.

Modafinil (Provigil) is a psychostimulant and cognitive enhancer drug, approved by the U.S. Food and Drug Administration for treating narcolepsy and other sleep disorders. Different studies showed that modafinil cognitive-enhancing properties improved outcome in the treatment of pathologic gamblers (Zack and Poulos, 2009), alcoholics (Schmaal et al., 2013), and patients suffering from other neuropsychiatric conditions (Scoriels et al., 2013). The use of modafinil as a treatment for cocaine and METH dependence remains inconclusive, with studies showing positive outcomes (Dackis et al., 2005; McGough et al., 2009) and studies showing promising but yet non-significant results in reducing drug use (Dackis et al, 2012; 
Shearer et al., 2009; Heinzerling et al., 2010). For both cocaine and METH users, modafinil was efficacious in improving several domains of cognitive and executive functions (Kalechstein et al, 2013; Gharemani et al., 2011; Kalechstein et al., 2010; Hester et al., 2010; Finke et al., 2010).

Modafinil's mechanism of action, although somewhat poorly understood, appears to involve multiple neurotransmitter systems. For example, modafinil can act as a weak DA transporter (DAT) inhibitor that increases extracellular DA levels (Mereu et al. 2013). Modafinil influences GABAergic, glutamatergic, noradrenergic, serotoninergic, histaminergic, and orexinergic systems (for a review see Mizenberg and Carter, 2008, Scoriels et al., 2013). In addition, modafinil enhances electrotonic coupling by increasing the effectiveness of gap junctions between neurons (Urbano et al., 2007; Garcia-Rill et al., 2007). We also demonstrated that modafinil can protect against METH toxicity (Raineri et al., 2011; 2012). Specifically, modafinil was able to prevent METH-induced toxic effects that included DA depletion and reductions in tyrosine hydroxylase (TH) and DAT levels in the striatum (Raineri et al., 2011). Furthermore, modafinil also attenuated METH-induced hyperthermia, glial activation, and increased expression of proapoptotic proteins (Raineri et al., 2012).

Compared to classical psychostimulants such as cocaine or amphetamine, the sites of action and behavioral effects of modafinil appear to be different (Mereu et al., 2013). Modafinil showed lower liability to abuse and lower risk of adverse effects on organ systems including the cardiovascular system (Minzenberg and Carter, 2008). Clinically relevant modafinil doses can robustly activate fronto-cortical areas involved in higher cognitive functions and a network of pro-arousing areas, which provide a plausible substrate for the wake-promoting and pro-cognitive effects of the drug (Gozzi et al., 2012). Of relevance to the present study, METH-dependent subjects showed a greater effect of modafinil on brain activation in bilateral insula/ventrolateral prefrontal cortex and anterior cingulate cortices than control participants, suggesting that modafinil improves learning in METH-dependent participants by enhancing neural function in those regions (Ghahremani et al., 2011).

The intracellular signaling pathways that mediate modafinil actions in fronto-cortical areas remain unknown. A potential candidate is the mitogen-activated protein kinase extracellular signal-regulated kinase (MAPK-ERK) cascade. The ERK1/2 pathway plays a critical role in memory function under physiological and pathological conditions (Mizoguchi et al. 2004; Kamei et al. 2006; Nagai et al. 2007, Cammarota et al., 2008). ERK1/2 signaling pathway linked to dopamine D1 receptors (Valjent et al., 2000; Zanassi et al., 2001) is involved in METH-associated contextual memory in rats (Mizoguchi et al., 2004). Additionally, it has been demonstrated that repeated METH treatment in mice induced cognitive impairment in a novel object recognition test, which was associated with deficits of the ERK1/2 pathway in the prefrontal cortex (PFC) (Kamei et al., 2006).

As it was mentioned above, there is only limited information on the mechanisms by which modafinil improves cognition in patients with addictive behaviors in terms of underlying neural substrates. Therefore, in the present study, we designed experiments aimed at testing modafinil's ability to improve cognitive deficits induced by sub-chronic METH treatment in mice. We used a novel object recognition (NOR) task, which is similar to visual recognition 
tests widely used in subhuman primates (Ennaceur, 2010), and is sensitive to METHinduced cognitive impairments (Bisagno et al., 2002; Kamei et al., 2006; Reichel et al., 2011). The NOR task evaluates the rodents' ability to recognize a novel object in the environment, and discrimination and memory performance is obtained upon identification of familiarity and novelty (Antunes and Biala, 2012). So, we also examined how modafinil and METH differentially modulated fronto-cortical phosphorylation of the MAPK isoforms, ERK1/ERK2 following exposure to novelty.

\section{MATERIALS AND METHODS}

\section{Animals}

C57BL/6 male mice (2-3 month-old) from the School of Exact and Natural Sciences of the University de Buenos Aires (UBA) were housed in a light and temperature-controlled room (12-h light/dark cycle, $22^{\circ} \mathrm{C}$ ), and were given free access to laboratory chow and tap water. Principles of animal care were followed in accordance with "Guidelines for the Care and Use of Mammals in Neuroscience and Behavioral Research" (National Research Council, 2003) and approved by Universidad de Buenos Aires authorities (Protocol Number: A5801-01) using OLAW and ARENA directives (NIH, Bethesda, USA).

\section{Pharmacological reagents}

Drugs were purchased from either Sigma (St. Louis, MO) or Tocris (Ellisville, MO).

Modafinil (racemic mixture of R- and S-enantiomers) was generously donated by Laboratorios Beta S.A. (Argentina).

\section{Drug treatments}

(+)-Methamphetamine hydrochloride (Sigma, St Louis, MO) was administered subcutaneously ( $\mathrm{sc}$ ) once a day for 7 days $(1 \mathrm{mg} / \mathrm{Kg}$, calculated as free base, dissolved in sterile saline solution). The METH regimen used in this study was performed according to studies by Kamei et al., (2006). Four days after the last METH injection, modafinil (30 or 90 $\mathrm{mg} / \mathrm{Kg}$, dissolved in DMSO-Arabic gum 5\% in sterile saline solution) was injected and 1 hour later mice were subjected to behavioral analysis (Novel Object Recognition task or Novelty exposure, Figure1A and 1B). Vehicle groups received the same volume of sterile saline and DMSO/Arabic gum/saline. Drugs were injected at a volume of $10 \mathrm{ml} / \mathrm{Kg}$ of body weight.

\section{Novel Object Recognition (NOR) task}

The NOR task was adapted according to previously reported methods (Kamei et al., 2006). The NOR task evaluates the rodents' ability to recognize a novel object in the environment. Basically, in the NOR task, there are no positive or negative reinforcers, and this methodology assesses the natural preference for novel objects displayed by rodents (Ennaceur, 2010). The task procedure consists of three phases: habituation, training, and a test phase. In the habituation phase, each animal is allowed to freely explore the arena in the absence of objects. The animal is then removed from the arena and placed in its cage. During the training phase, a single animal is placed in the arena containing two identical sample objects $(\mathrm{A}+\mathrm{A})$ for 5 minutes. The experimental context is not drastically different 
during the training and the test phase. After a retention interval begins the test phase, and the animal is returned to the arena with two objects, one is identical to the sample and the other is novel $(\mathrm{A}+\mathrm{B})$. In our experiments, exploration occurred in an open-top arena $(40 \mathrm{~cm} 3)$ made of plexiglass, with the floor covered with clean woodchip bedding. Testing was done during the light phase (8 AM- $8 \mathrm{PM}$ ), in a sound-attenuated room, with dimmed illumination $(40 \mathrm{~W})$. Mice were individually habituated to the box for 5 min during three consecutive days after the last METH injection, in the absence of objects (Figure 1B: habituation sessions, withdrawal days 1-3). On the fourth day after METH, two identical objects were symmetrically fixed to the floor of the box, $8 \mathrm{~cm}$ from one of the walls, and each mouse was allowed to explore the box for 10 min (Figure 1B: training session, withdrawal day 4). Objects were: golf balls, plastic pipes ( $3 \mathrm{~cm}$ diameter, $8 \mathrm{~cm}$ high) and plastic cubes $(4 \mathrm{~cm} 3)$, all of which were similar in size but different in color, shape and brightness. Sets of objects were chosen based on preliminary experiments that indicated that they were similarly preferred. Objects were washed with $40 \%$ ethanol solution between trials. Following a 24-hour delay, mice were placed back in the box for 5 min where one of the familiar objects was replaced by a novel object (Figure 1B: retention session, withdrawal day 5). The positions of the objects in the test and the objects used as novel or familiar were counterbalanced between the animals in each group and between the control and drugtreated groups. All sessions were recorded and analyzed with Ethovision XT 7.0 tracking software (Noldus, The Netherlands), using nose point-tail base detection. The percentage of exploratory preference $(\% \mathrm{EP})$ was calculated as exploration time of the novel object $(\mathrm{TN})$ divided by the total exploration time of both novel (TN) and familiar (TF) objects $[\% \mathrm{EP}=\mathrm{TN} /(\mathrm{TN}+\mathrm{TF}) * 100]$. Similarly, this calculation can be applied when both objects are identical, in the training session phase, but here the mathematic formula will be exploration time of the right object (TR) divided by the total exploration time of both right (TR) and left (TL) objects [\% $\mathrm{EP}=\mathrm{TR} /(\mathrm{TR}+\mathrm{TL}) * 100]$.

\section{Novelty effect}

In a separate set of experiments, mice were individually habituated to object recognition box for 5 min during three consecutive days after the last METH injection (in the absence of objects). On the METH withdrawal day 4, mice were placed in the arena for 10 minutes with objects (Novelty) or without objects (Control) (Figure 1B), and then immediately euthanized. Brains were quickly removed and brain areas were dissected out on an ice-cold plate. Each tissue sample was frozen and stored at $-70{ }^{\circ} \mathrm{C}$ until processed.

\section{Exploratory activity}

We investigated the effect of early METH withdrawal on exploratory activity. Spontaneous locomotor activity was recorded during habituation sessions to the object recognition arena using Ethovision XT 7.0 tracking software (Noldus, The Netherlands). We analyzed locomotor activity (distance travelled) and time spent in the center area of the arena during the 5-min habituation sessions. The center area was defined as one half the total area of the arena. 


\section{Western blot}

We measured ERK and phosphorylated ERK (pERK) protein expression by Western blot in brain areas of mice subjected to the novelty effect. Brains were removed rapidly after Novelty and Control sessions and brain sections were dissected out and stored at $-70{ }^{\circ} \mathrm{C}$. Tissue homogenates were prepared in a solution containing $50 \mathrm{mM}$ Tris- $\mathrm{HCl} \mathrm{pH} 7.5,150$ $\mathrm{mM} \mathrm{NaCl}, 0.1 \%$ Triton X100, $0.5 \%$ sodium deoxycholate, $0.1 \%$ SDS, $1 \mathrm{mM}$ PMSF, $5 \mu \mathrm{g} / \mathrm{ml}$ leupeptin, and $5 \mu \mathrm{g} / \mathrm{ml}$ aprotinin. After removal of cell debris by centrifugation, the protein concentration of the cell lysate was determined. The homogenates were combined with loading buffer containing $4 \%$ SDS, $20 \%$ glycerol, $10 \% \beta$-mercaptoethanol, $125 \mathrm{mM}$ Tris, (pH 6.8), and boiled at $100{ }^{\circ} \mathrm{C}$ for $5 \mathrm{~min}$. Protein samples ( $50 \mu \mathrm{g}$ ) were separated by $12.5 \%$ SDS-PAGE, and the separated proteins transferred to a PVDF membrane. Immunoblotting was performed using a mouse monoclonal antibody to pERK1/2 (1:500, E-4 sc-7373 Santa Cruz Biotechnology), then membranes were stripped and reprobed with polyclonal rabbit antibody to total ERK2 (1:2000, C-14 sc-154 Santa Cruz Biotechnology). Because there was no change in the levels of total ERK, values of pERK were normalized to the values of total ERK. Immune complexes were detected with anti-mouse and anti-rabbit secondary antibodies and chemiluminescence reagents (Amersham, NJ, USA). Bands were quantified using ImageJ (NIH).

\section{Statistical analysis}

InfoStat software (www.infostat.com.ar) was used for statistical comparisons. Statistics were performed using either one-way (treatment) or two-way (novelty and treatment) ANOVA followed by Bonferroni post hoc tests or planned contrasts. Data were transformed when required. Kruskal Wallis ANOVA on Ranks was performed when data did not comply with the assumptions of parametric tests. For the analysis of exploratory activity during habituation sessions, repeated measures two-way ANOVA followed by Bonferroni was performed. Differences were considered significant if $\mathrm{p}<0.05$.

\section{RESULTS}

\section{Effects of modafinil and methamphetamine on exploratory activity and object recognition memory}

1.a Effect of methamphetamine withdrawal on exploratory activity-As shown in Figure 1A, mice were treated with a chronic METH or vehicle protocol (METH 1 $\mathrm{mg} / \mathrm{Kg} /$ day for 7 consecutive days). Next, mice were placed in an object recognition arena 5min a day for 3 consecutive days, as part of the habituation sessions for the NOR task. We recorded these habituation sessions and analyzed exploratory activity during METH withdrawal, measuring locomotion and time spent in the center of the arena (Figure 2). Repeated measures two-way ANOVA for locomotion showed significant day effect $[F(2,50)=21.75, p<0.001]$, but no treatment or interaction effect (Figure 2A). Bonferroni post hoc test showed that on day 1 of withdrawal both METH- and vehicle-treated mice manifested increased locomotion ( $\mathrm{p}<0.05$ ), compared to day 2 and 3 , suggesting habituation to the object recognition arena. Repeated measures two-way ANOVA for time in center showed significant treatment $[\mathrm{F}(1,50)=5.14, \mathrm{p}<0.05]$, day $[\mathrm{F}(2,50)=18.81, \mathrm{p}<0.001]$, and interactive $[F(2,50)=3.69, p<0.05]$ effects (Figure $2 B$ ). Bonferroni post hoc test showed that 
on day 2 the Vehicle group diminished the time spent in the center $(\mathrm{p}<0.05)$, while the METH group did not. On day 3 both groups spent similar amounts of time exploring the center. These results indicate that, by the time training sessions of the NOR task had started, both METH and control mice showed similar exploratory activity and were similarly habituated to the object recognition arena.

\section{1.b Acute modafinil effects on methamphetamine withdrawal: object} recognition memory-On day 4 of withdrawal, mice received acute vehicle, 30 or 90 $\mathrm{mg} / \mathrm{Kg}$ modafinil dose and $1 \mathrm{hr}$ later performed the training session of the NOR task. As expected, one way ANOVA found no significant differences in the exploratory preference for the training sessions after either 30 or $90 \mathrm{mg} / \mathrm{Kg}$ modafinil (Figure $3 \mathrm{~A}$ and $\mathrm{B}$ ). The retention session was performed $24 \mathrm{hrs}$ later, and both $30 \mathrm{mg} / \mathrm{Kg}$ and $90 \mathrm{mg} / \mathrm{Kg}$ modafinil groups showed significant treatment effect (modafinil $30 \mathrm{mg} / \mathrm{Kg}$ : Kruskal Wallis ANOVA on ranks [H=10.26, $\mathrm{p}<0.05]$; modafinil $90 \mathrm{mg} / \mathrm{Kg}$ retention session: one way ANOVABonferroni $[F(3,70)=8.11, \mathrm{p}<0.001])$. For both 30 and $90 \mathrm{mg} / \mathrm{Kg}$ groups, post hoc tests showed impaired object recognition memory in METH-treated mice, evidenced by similar preference of familiar and novel objects during the retention session of the NOR task (Figure $3 \mathrm{~A}$ and $\mathrm{B}$ ). Acute $30 \mathrm{mg} / \mathrm{Kg}$ modafinil did not improve object recognition deficits observed in METH-treated mice (Figure 3A). Modafinil at a higher dose, $90 \mathrm{mg} / \mathrm{Kg}$, improved METH-induced object recognition deficits, evidenced by a significant increase in the preference index in the METH-MOD group compared to the METH group $(\mathrm{p}<0.05)$, to values comparable to those of the Vehicle group (Figure 3B). Modafinil-treated subjects (for 30 and $90 \mathrm{mg} / \mathrm{Kg}$ ) showed preference values similar to the Vehicle group, and significantly higher compared to those of the METH group ( $p<0.05$ ). Total time spent in object exploration during the training and retention sessions did not differ among groups for the two modafinil doses (Figure 3C and D). These results suggest that chronic METH treatment did not have an effect on motivation and exploration, suggesting METH-induced memory impairment rather than a lack of interest in novel stimuli. We also measured locomotor activity during training and retention sessions (Figure $3 \mathrm{E}$ and F). Both $30 \mathrm{mg} / \mathrm{Kg}$ and 90 $\mathrm{mg} / \mathrm{Kg}$ modafinil groups showed significant treatment effect in the training session (MOD $30 \mathrm{mg} / \mathrm{Kg}$ : one way ANOVA-Bonferroni [F(3,38)=11.45, p<0.001]; MOD $90 \mathrm{mg} / \mathrm{Kg}$ : one way ANOVA-Bonferroni $[\mathrm{F}(3,77)=66.47, \mathrm{p}<0.001])$. Post hoc tests showed no differences in locomotor activity of Vehicle- and METH-treated mice, while the acutely MOD-treated mice (MOD and METH-MOD groups) showed an increase in locomotor activity compared to Vehicle and METH groups at both modafinil doses $(\mathrm{p}<0.05)$. It is noteworthy that the 90 $\mathrm{mg} / \mathrm{Kg}$ the METH-MOD group exhibited higher locomotor activity compared with modafinil group values $(\mathrm{p}<0.05)$ (Figure 3E). One way ANOVA found no significant differences in locomotion for the retention sessions in either 30 or $90 \mathrm{mg} / \mathrm{Kg}$ modafinil groups. In addition, modafinil-induced improvement of object recognition memory deficits after METH was replicated in female mice (data not shown). We used the same protocol previously described for male mice using modafinil at a dose that showed positive results, i.e. $90 \mathrm{mg} / \mathrm{Kg}$. Exploratory preferences in retention session (\%) were as follows: Vehicle: 65.01 \pm 4.20 [a], MOD: 66.34 \pm 3.61 [a], METH: 44.91 \pm 8.41 [b], METH-MOD: 66.21 \pm 7.01 [a], one way ANOVA-Bonferroni $[\mathrm{F}(3,24)=3.02, \mathrm{p}<0.05]$. 


\section{Effects of modafinil and methamphetamine locomotor activity and ERK phosphorylation induced by novelty}

The results obtained in the NOR task showed that modafinil, given at a high $90 \mathrm{mg} / \mathrm{Kg}$ dose before the first exposure to novel objects, was able to enhance long-term memory retention by restoring the novelty preference in a retention session performed $24 \mathrm{hrs}$ later. As mentioned above, the NOR task evaluates the rodents' ability to recognize a novel object in the environment and discrimination and memory performance is obtained upon identification of familiarity and novelty (Antunes and Biala, 2012). Novelty is a change from expected likelihood of an event on the basis of both previous information and internal estimates of conditional probabilities (Antunes and Biala, 2012). Animals can be affected by a novel stimulus; i.e. novelty can change the animals' behavior, induce stress responses, and elicit approach behavior (Bevins et al., 2002). Therefore, we conducted separate experiments in mice subjected to METH withdrawal aimed at investigating novelty-induced changes on mPFC ERK phosphorylation and exploratory activity with or without modafinil administration.

\section{2.a Effect of acute modafinil on mice exposed to novel objects during methamphetamine withdrawal: locomotor activity-To asses novelty-induced} locomotor activity, mice were placed in the arena with or without objects (Novelty and Control groups, respectively) for $10 \mathrm{~min}$, and euthanized immediately (Figure 1B). We recorded Control and Novelty sessions and analyzed locomotor activity. For the $30 \mathrm{mg} / \mathrm{Kg}$ modafinil group, two way ANOVA showed significant treatment effect $[\mathrm{F}(3,33)=56.45$, $\mathrm{p}<0.001]$, but no novelty or interactive effects. For the $90 \mathrm{mg} / \mathrm{Kg}$ modafinil group, two way ANOVA showed significant treatment $[\mathrm{F}(3,62)=53.30, \mathrm{p}<0.001]$, novelty $[\mathrm{F}(1,62)=10.43$, $\mathrm{p}<0.01]$, and interactive $[\mathrm{F}(3,62)=3.33, \mathrm{p}<0.05]$ effects. Bonferroni post hoc tests demonstrated that Vehicle and METH groups showed neither treatment nor novelty effects on locomotion (Figure 4A and B). Mice given acute $30 \mathrm{mg} / \mathrm{Kg}$ modafinil displayed only a main treatment effect, evidenced by MOD and METH-MOD groups showing increased locomotion compared with Vehicle and METH groups (Figure 4A). In agreement with locomotor responses obtained in mice while performing the NOR task (Figure 3E), the MOD and METH-MOD groups receiving $30 \mathrm{mg} / \mathrm{Kg}$ modafinil showed similar locomotor effects. In mice receiving acute $90 \mathrm{mg} / \mathrm{Kg}$ MOD (Figure 4B), we found elevated locomotion in the MOD and METH-MOD groups compared to Vehicle and METH groups; also, with the $90 \mathrm{mg} / \mathrm{Kg}$ dose the METH-MOD group showed higher locomotion than the MOD group. This is in agreement with locomotor responses obtained for the same dose in the NOR task (Figure 3F). We also found within the METH-MOD group increased locomotion in the novelty group when compared to the control group $(\mathrm{p}<0.05)$.

\section{2.b Effect of acute modafinil on mice exposed to novel objects during methamphetamine withdrawal: ERK phosphorylation in MPFC—It was} previously shown that one of the molecular mechanisms involved in METH-induced object recognition deficits involve a failure in mPFC ERK phosphorylation after exposure to novel objects (Kamei et al., 2006). Thus, we decided to investigate if modafinil would be able to restore ERK signaling pathway in the $\mathrm{mPFC}$ after a Novelty exposure. For both $30 \mathrm{mg} / \mathrm{Kg}$ and $90 \mathrm{mg} / \mathrm{Kg}$ modafinil experiments, two way ANOVA showed significant novelty effect 
[modafinil $30 \mathrm{mg} / \mathrm{Kg}: \mathrm{F}(1,35)=5.41$, $\mathrm{p}<0.05$; modafinil $90 \mathrm{mg} / \mathrm{Kg}: \mathrm{F}(1,47)=10.33$, $\mathrm{p}<0.01$ ], but no treatment or interactive effects. For both experiments, planned contrasts comparing control vs. novelty within each treatment revealed a significant increase in ERK phosphorylation in the mPFC of the Vehicle and MOD groups immediately after the Novelty session ( $\mathrm{p}<0.05)$, which was abolished in the METH group. We found that, in agreement with the retention results obtained in the NOR task, METH-MOD group receiving acute 30 $\mathrm{mg} / \mathrm{Kg}$ modafinil showed no novelty-induced increase in ERK phosphorylation (Figure 5A). In mice that received $90 \mathrm{mg} / \mathrm{Kg}$ modafinil we observed that the novelty-induced ERK phosphorylation was restored $(\mathrm{p}<0.05)$ (Figure 5B). The levels of total ERK did not differ between experimental groups in any case [modafinil $30 \mathrm{mg} / \mathrm{Kg}: \mathrm{F}(7,35)=1.75, \mathrm{p}>0.05$; modafinil $90 \mathrm{mg} / \mathrm{Kg}$ : $\mathrm{F}(7,47)=1.00, \mathrm{p}>0.05]$.

\section{2.c Effect of acute modafinil on mice exposed to novel objects during methamphetamine withdrawal: ERK phosphorylation in the NAc and}

hippocampus-The hippocampus participates in the formation and consolidation of new memories and it was previously shown that MAPK and ERK play important roles (Cammarota et al., 2008). Therefore, we measured novelty-induced ERK phosphorylation in the hippocampus of METH-treated mice, with or without an injection of $90 \mathrm{mg} / \mathrm{Kg}$ modafinil (Figure 6A). We found no changes in ERK phosphorylation in the hippocampus in any group subjected to the novelty effect $[F(7,31)=1.00, p>0.05]$ (Figure $6 \mathrm{~A}$ ). The levels of total ERK did not differ between experimental groups in any condition $[\mathrm{F}(7,31)=1.24$, $\mathrm{p}>0.05]$.

There is evidence suggesting that the NAc is involved in the behavioral response to novelty and other tasks that rely on familiarity discrimination (Sargolini et al., 2003; Nelson et al., 2010). Therefore, we evaluated novelty-induced ERK phosphorylation in the NAc of METH-treated mice, with or without an injection of $90 \mathrm{mg} / \mathrm{Kg}$ modafinil (Figure 6B). We found no changes in ERK phosphorylation in NAc in any group subjected to the novelty effect $[\mathrm{F}(7,26)=0.35, \mathrm{p}>0.05]$. The levels of total ERK did not differ between experimental groups in any condition $[\mathrm{F}(7,26)=0.96, \mathrm{p}>0.05]$.

\section{DISCUSSION}

The main finding of this study is that acute modafinil administration improved METHinduced object recognition memory deficits. METH-treated mice also showed a failure in ERK phosphorylation in the mPFC, which, in rodents, is detected shortly after a novel object is presented for exploration (Kamei et al., 2006; Nagai et al., 2007). Modafinil administration also restored novelty-induced ERK phosphorylation in the mPFC. To our knowledge, this is the first study addressing modafinil's beneficial effects on the visual recognition deficits induced by METH in an animal model. Modafinil also showed positive effects in animal models of neurodegeneration (Garcia et al., 2013). Interestingly, modafinil did not modify cognition in naïve rats but was able to reverse memory deficits induced by iron overload, a model of memory impairment related to neurodegenerative disorders (Garcia et al., 2013). Furthermore, these authors used several doses of MOD $(0.75,7.5$ or 75 $\mathrm{mg} / \mathrm{Kg}$ ) and found that only the highest dose tested $(75 \mathrm{mg} / \mathrm{Kg}$ ) was able to restore object recognition deficits (Garcia et al., 2013). These data are in agreement with results from the 
present study since we have observed that modafinil was only effective at a dose of 90 $\mathrm{mg} / \mathrm{Kg}$, while $30 \mathrm{mg} / \mathrm{Kg}$ modafinil did not show protective effects. Our results are also in agreement with previous studies in humans, where modafinil administration was able to improve cognitive deficits and prefrontal cortical function only in METH-dependent subjects (Gharemani et al., 2011). Additionally, it has been shown that modafinil is more effective in individuals who perform poorly on cognitive tasks relative to those subjects who perform better, indicating that modafinil does not enhance baseline performance but improves cognition in subjects with evident cognitive impairments (Kalechstein et al., 2010; Finke et al., 2010). Recent clinical studies showed that modafinil oral administration in METH users with 7 days of abstinence, at a dose recommended for the treatment of sleeping disorders (200 mg, once daily), although improved several domains of executive function, had no effect on visual memory performance (Hester et al., 2010). Accordingly, Finke and coworkers (2010) showed improved visual processing in participants with low performance baseline when using a higher modafinil dose (400 mg once daily). All together, these results from clinical and pre- clinical studies suggest that a high dose of modafinil might be needed in order to achieve improvements in cognitive functions.

The mPFC mediates executive function and decision making processes, and is therefore a key neuroanatomical region in addictive behaviors (Schoenbaum and Shaham, 2008). Studies using functional magnetic resonance imaging have shown that PFC dysfunction in METH abusers is associated with cognitive impairment (Paulus et al., 2002), probably linked to deficits in DA neurotransmission (Tritsch and Sabatini, 2012). Although the effects of modafinil on midbrain DA neuronal activity remain inconsistent, modafinil acts as a weak DAT inhibitor (Mereu et al., 2013). Consequently, it has been shown that acute modafinil administration increased extracellular DA levels in the mPFC (de Saint Hilaire et al., 2001), the striatum of rodents (Dopheide et al., 2007; Nguyen et al., 2011; Young et al., 2011) and humans (Volkow et al., 2009). Acute modafinil also induced a strong activation in those areas, measured using PET and confirmed by c-Fos immunoreactivity (Gozzi et al., 2012).

Modafinil was also found to rescue visual object recognition in a rat model of schizophrenia (Redrobe et al., 2010), which is a condition that presents with diminished dopamine neurotransmission in PFC (Okubo et al., 1997). Thus, modafinil's ability to enhance cognitive performance in METH abusers might be associated with modafinil's actions on the DAT (Mereu et al. 2013), stimulating dopaminergic neurotransmission in the mesocorticolimbic system.

It is known that ERK, a member of the MAPK family, is critically linked to dopaminergic neurotransmission and long-term memory retention, but not memory acquisition or short term memory (Valjent et al 2000; Nagai et al., 2007). ERK signaling is activated by stimuli associated with synaptic activity and plasticity, like calcium influx and neurotrophins, and its activation mediates, in part, new mRNA and protein synthesis necessary for long-term memory storage (Cammarota et al., 2008; Kelly et al., 2003). There is also accumulating evidence implicating the ERK pathway in behavioral responses to addictive drugs such as METH and cocaine (Mizoguchi et al 2004; Valjent et al 2000). ERK expression is especially abundant in the mesocorticolimbic DA system, a distribution that underscores the importance of the ERK signaling cascade in mediating DA function (Valjent et al., 2004). ERK signaling is also known to be critically linked to DA D1 receptor activation, which 
couples with Gs proteins leading to cAMP and PKA cascade activation (Valjent et al., 2000; Nagai et al., 2007). Activated ERK can promote the expression of genes associated with memory and learning, in part, by activating transcription factors such as CREB and Elk-1, which in turn activate gene transcription involved in synaptic and neuronal plasticity such as c-Fos, Zif268, etc. (Cammarota et al., 2008; Zhai et al., 2008). Our results indicate that modafinil modulates ERK phosphorylation in $\mathrm{MPFC}$ in a dose-dependent manner, which might be related to modafinil's ability to enhance DA neurotransmission and stimulation of D1 receptors (Young and Geyer, 2010).

It is well known that repeated exposure to drugs of abuse results in a progressive and longlasting enhancement of the locomotor response, a phenomenon termed psychomotor (or locomotor) sensitization (Robinson and Berridge, 1993). It is also of interest to discuss our results showing that modafinil induced a cross-sensitization effect with METH. We showed that the same modafinil dose that enhanced visual retention in METH-treated mice, 90 $\mathrm{mg} / \mathrm{Kg}$, also elicited a cross-sensitization effect in locomotion. A previous study in mice also found locomotor cross-sensitization between METH and modafinil assessed by challenging modafinil -pretreated mice with $1 \mathrm{mg} / \mathrm{Kg} \mathrm{METH}$, and METH-pretreated mice with 50 $\mathrm{mg} / \mathrm{Kg}$ modafinil (Soeiro et al., 2012). Our results on cross-sensitization between METH and modafinil raise the possibility that neuroadaptations induced by METH and evidenced by acute administration of modafinil might be related to the beneficial effects of modafinil on cognition.

There is some discrepancy in the role of novelty-mediated ERK signaling in the hippocampus, since ERK hyperphosphorylation after training session was observed in rats (Kelly et al., 2003), but not in mice (Kamei et al., 2006). In the present study, we found no novelty-mediated changes in ERK phosphorylation in the hippocampus of the experimental groups, in agreement with the studies performed by Kamei and co-workers (2006) in ICR mice. A possible explanation for the differences observed between species may be that the study performed in rats analyzed specifically the dentate gyrus and CA1 regions of the hippocampus, while the studies in mice where performed on the whole structure, which may have diluted the differences. Nonetheless, our results are in agreement with recent reports showing that the hippocampus, together with the perirhinal and the prefrontal cortices, is involved in the object location and object-in-place tasks, which have a spatial processing component, but not in the novel object recognition task (Forwood et al., 2005; Barker and Warburton, 2011). We also found no novelty-mediated ERK phosphorylation in the NAc of the experimental groups. The role of NAc in novelty processing is controversial, with reports indicating a NAc role only in tasks that involve spatial processing (Mele et al., 2004; Nelson et al., 2010), and reports indicating that the NAc also participates in visual object (nonspatial) processing (Sargolini et al., 2003). Our results indicate that, whether or not the NAc is involved in novelty processing, the ERK pathway in this structure was not affected by either METH or modafinil.

Imaging studies show that drug abusers have marked decreases in DA receptors and DA release. This decrease in DA function is associated with reduced activity in brain areas that mediate inhibitory control and executive function, such as the cingulate gyrus and the dorsolateral PFC. Deficits in DA activity, linked with prefrontal and striatal deregulation, 
play a central role in the loss of control and compulsive drug intake behavior (Volkow et al., 2009). Although the mechanisms underlying modafinil-induced improvements in prefrontal function and cognitive performance have yet to be delineated, our results further support the notion that modafinil represents an effective therapeutic intervention aimed at restoring brain dopaminergic tone, and therefore restoring intracellular pathways like the MAPK-ERK pathway in the PFC. Moreover, results from the present study further support the hypothesis that drugs that could modulate ERK pathways might in turn be useful for the treatment of the cognitive consequences of drug abuse. Specifically, our results point to modafinil as a good candidate for the treatment of METH dependence, considering modafinil therapy as an agonist-like replacement therapy (Herin et al., 2010).

\section{Acknowledgments}

Dr. Bisagno has been authorized to study drug abuse substances in animal models by A.N.M.A.T. (National Board of Medicine Food and Medical Technology, Ministerio de Salud, Argentina). Dr. Betina Gonzalez is a recipient of a Postdoctoral Award from Fundación Bunge y Born. This work is supported by grants PIP 11420100100072 and PICT 2012-0924, Argentina, and by NIH award P20 GM103425 to the Center for Translational Neuroscience.

\section{REFERENCES}

Antunes M, Biala G. The novel object recognition memory: neurobiology, test procedure, and its modifications. Cognitive Processing. 2012; 13(2):93-110. [PubMed: 22160349]

Bamford NS, Zhang H, Joyce JA, Scarlis CA, Hanan W, Wu NP, André VM, Cohen R, Cepeda C, Levine MS, Harleton E, Sulzer D. Repeated exposure to methamphetamine causes long-lasting presynaptic corticostriatal depression that is renormalized with drug readministration. Neuron. 2008; 58(1):89-103. [PubMed: 18400166]

Barker GR, Warburton EC. When is the hippocampus involved in recognition memory? J Neurosci. 2011; 31(29):10721-10731. [PubMed: 21775615]

Bevins RA, Besheer J, Palmatier MI, Jensen HC, Pickett KS, Eurek S. Novel-object place conditioning: behavioral and dopaminergic processes in expression of novelty reward. Behav Brain Res. 2002; 129(1-2):41-50. [PubMed: 11809493]

Bisagno V, Ferguson D, Luine VN. Short toxic methamphetamine schedule impairs object recognition task in male rats. Brain Res. 2002; 940(1-2):95-101. [PubMed: 12020880]

Cammarota M, Bevilaqua LR, Medina JH, Izquierdo I. ERK1/2 and CaMKII-mediated events in memory formation: is 5HT regulation involved? Behav Brain Res. 2008; 195(1):120-128. [PubMed: 18242725]

Dackis CA, Kampman KM, Lynch KG, Pettinati HM, O'Brien CP. A double-blind, placebo-controlled trial of modafinil for cocaine dependence. Neuropsychopharmacology. 2005; 30(1):205-211. [PubMed: 15525998]

Dackis CA, Kampman KM, Lynch KG, Plebani JG, Pettinati HM, Sparkman T, O'Brien CP. A doubleblind, placebo-controlled trial of modafinil for cocaine dependence. J Subst Abuse Treat. 2012; 43(3):303-312. [PubMed: 22377391]

de Saint Hilaire Z, Orosco M, Rouch C, Blanc G, Nicolaidis S. Variations in extracellular monoamines in the prefrontal cortex and medial hypothalamus after modafinil administration: a microdialysis study in rats. Neuroreport. 2001; 12(16):3533-3537. [PubMed: 11733706]

Dopheide MM, et al. Modafinil evokes striatal [(3)H]dopamine release and alters the subjective properties of stimulants. European Journal of Pharmacology. 2007; 568(1-3):112-123. [PubMed: 17477916]

Ennaceur A. One-trial object recognition in rats and mice: methodological and theoretical issues. Behav Brain Res. 2010; 215(2):244-254. [PubMed: 20060020]

Feltenstein MW, See RE. The neurocircuitry of addiction: an overview. Br J Pharmacol. 2008; 154:261-274. [PubMed: 18311189] 
Finke K, Dodds CM, Bublak P, Regenthal R, Baumann F, Manly T, Müller U. Effects of modafinil and methylphenidate on visual attention capacity: a TVA-based study. Psychopharmacology (Berl). 2010; 210(3):317-329. [PubMed: 20352415]

Forwood SE, Winters BD, Bussey TJ. Hippocampal lesions that abolish spatial maze performance spare object recognition memory at delays of up to 48 hours. Hippocampus. 2005; 15(3):347-355. [PubMed: 15558543]

Garcia VA, Souza de Freitas B, Busato SB, D'avila Portal BC, Piazza FC, Schröder N. Differential effects of modafinil on memory in naïve and memory-impaired rats. Neuropharmacology. 2013; 75C:304-311. [PubMed: 23958446]

Garcia-Rill E, Heister DS, Ye M, Charlesworth A, Hayar A. Electrical coupling: novel mechanism for sleep-wake control. Sleep. 2007; 30(11):1405-1414. [PubMed: 18041475]

Ghahremani DG, Tabibnia G, Monterosso J, Hellemann G, Poldrack RA, London ED. Effect of modafinil on learning and task-related brain activity in methamphetamine-dependent and healthy individuals. Neuropsychopharmacology. 2011; 36(5):950-959. [PubMed: 21289606]

Gozzi A, Colavito V, Seke Etet PF, Montanari D, Fiorini S, Tambalo S, Bifone A, Zucconi GG, Bentivoglio M. Modulation of fronto-cortical activity by modafinil: a functional imaging and fos study in the rat. Neuropsychopharmacology. 2012; 37(3):822-837. [PubMed: 22048464]

Heinzerling KG, Swanson AN, Kim S, Cederblom L, Moe A, Ling W, Shoptaw S. Randomized, double-blind, placebo-controlled trial of modafinil for the treatment of methamphetamine dependence. Drug Alcohol Depend. 2010; 109(1-3):20-29. [PubMed: 20092966]

Herin DV, Rush CR, Grabowski J. Agonist-like pharmacotherapy for stimulant dependence: preclinical, human laboratory, and clinical studies. Ann N Y Acad Sci. 2010; 1187:76-100. [PubMed: 20201847]

Hester R, Lee N, Pennay A, Nielsen S, Ferris J. The effects of modafinil treatment on neuropsychological and attentional bias performance during 7-day inpatient withdrawal from methamphetamine dependence. Exp Clin Psychopharmacol. 2010; 18(6):489-497. [PubMed: 21186923]

Kalechstein AD, De La Garza R 2nd, Newton TF. Modafinil administration improves working memory in methamphetamine-dependent individuals who demonstrate baseline impairment. Am J Addict. 2010; 19(4):340-344. [PubMed: 20653641]

Kalechstein AD, Mahoney JJ 3rd, Yoon JH, Bennett R, De la Garza R 2nd. Modafinil, but not escitalopram, improves working memory and sustained attention in long-term, high-dose cocaine users. Neuropharmacology. 2013; 64:472-478. [PubMed: 22796108]

Kamei H, Nagai T, Nakano H, Togan Y, Takayanagi M, Takahashi K, Kobayashi K, Yoshida S, Maeda K, Takuma K, Nabeshima T, Yamada K. Repeated methamphetamine treatment impairs recognition memory through a failure of novelty-induced ERK activation in the prefrontal cortex of mice. Biol Psychiatry. 2006; 59(1):75-84. [PubMed: 16139811]

Kauer JA, Malenka RC. Synaptic plasticity and addiction. Nat Rev Neurosci. 2007; 8:844-858. [PubMed: 17948030]

Kelly A, Laroche S, Davis S. Activation of mitogen-activated protein kinase/extracellular signalregulated kinase in hippocampal circuitry is required for consolidation and reconsolidation of recognition memory. J Neurosci. 2003; 23(12):5354-5360. [PubMed: 12832561]

Krasnova IN, Cadet JL. Methamphetamine toxicity and messengers of death. Brain Res Rev. 2009; 60(2):379-340. [PubMed: 19328213]

McGaugh J, Mancino MJ, Feldman Z, Chopra MP, Gentry WB, Cargile C, Oliveto A. Open-label pilot study of modafinil for methamphetamine dependence. J Clin Psychopharmacol. 2009; 29(5):488491. [PubMed: 19745650]

Mele A, Avena M, Roullet P, De Leonibus E, Mandillo S, Sargolini F, Coccurello R, Oliverio A. Nucleus accumbens dopamine receptors in the consolidation of spatial memory. Behav Pharmacol. 2004; 15(5-6):423-431. [PubMed: 15343069]

Mereu M, Bonci A, Newman AH, Tanda G. The neurobiology of modafinil as an enhancer of cognitive performance and a potential treatment for substance use disorders. Psychopharmacology. 2013; 229(3):415-434. [PubMed: 23934211] 
Miller CA, Campbell SL, Sweatt JD. DNA methylation and histone acetylation work in concert to regulate memory formation and synaptic plasticity. Neurobiol Learn Mem. 2008; 89(4):599-603. [PubMed: 17881251]

Minzenberg MJ, Carter CS. Modafinil: a review of neurochemical actions and effects on cognition. Neuropsychopharmacology. 2008 Jun; 33(7):1477-1502. [PubMed: 17712350]

Mizoguchi H, Yamada K, Mizuno M, Mizuno T, Nitta A, Noda Y, Nabeshima T. Regulations of methamphetamine reward by extracellular signal-regulated kinase 1/2/ets-like gene-1 signaling pathway via the activation of dopamine receptors. Mol Pharmacol. 2004; 65(5):1293-1301. [PubMed: 15102958]

Monterosso JR, Aron AR, Cordova X, Xu J, London ED. Deficits in response inhibition associated with chronic methamphetamine abuse. Drug and Alcohol Dependence. 2005; 79(2):273-277. [PubMed: 15967595]

Morgan EE, Woods SP, Poquette AJ, Vigil O, Heaton RK, Grant I. Visual memory in methamphetamine-dependent individuals: deficient strategic control of encoding and retrieval. Aust N Z J Psychiatry. 2012; 46(2):141-152. [PubMed: 22311530]

Nagai T, Takuma K, Kamei H, Ito Y, Nakamichi N, Ibi D, Nakanishi Y, Murai M, Mizoguchi H, Nabeshima T, Yamada K. Dopamine D1 receptors regulate protein synthesis-dependent long-term recognition memory via extracellular signal-regulated kinase $1 / 2$ in the prefrontal cortex. Learn Mem. 2007; 14(3):117-125. [PubMed: 17337702]

Nelson AJ, Thur KE, Marsden CA, Cassaday HJ. Dissociable roles of dopamine within the core and medial shell of the nucleus accumbens in memory for objects and place. Behav Neurosci. 2010; 124(6):789-799. [PubMed: 21133535]

Nguyen TL, Tian YH, You IJ, Lee SY, Jang CG. Modafinil-induced conditioned place preference via dopaminergic system in mice. Synapse. 2011; 65(8):733-741. [PubMed: 21157933]

Nordahl TE, Salo R, Leamon M. Neuropsychological effects of chronic methamphetamine use on neurotransmitters and cognition: A review. J Neuropsychiatry Clin Neurosci. 2003; 15(3):317325. [PubMed: 12928507]

Okubo Y, Suhara T, Suzuki K, Kobayashi K, Inoue O, Terasaki O, Someya Y, Sassa T, Sudo Y, Matsushima E, Iyo M, Tateno Y, Toru M. Decreased prefrontal dopamine D1 receptors in schizophrenia revealed by PET. Nature. 1997; 385(6617):634-636. [PubMed: 9024661]

Paulus MP, Hozack NE, Zauscher BE, Frank L, Brown GG, Braff DL, Schuckit MA. Behavioral and functional neuroimaging evidence for prefrontal dysfunction in methamphetamine-dependent subjects. Neuropsychopharmacology. 2002 Jan; 26(1):53-63. [PubMed: 11751032]

Raineri M, Gonzalez B, Goitia B, Garcia-Rill E, Krasnova IN, Cadet JL, Urbano FJ, Bisagno V. Modafinil abrogates methamphetamine-induced neuroinflammation and apoptotic effects in the mouse striatum. PLoS One. 2012; 7(10):e46599. [PubMed: 23056363]

Raineri M, Peskin V, Goitia B, Taravini IR, Giorgeri S, Urbano FJ, Bisagno V. Attenuated methamphetamine induced neurotoxicity by modafinil administration in mice. Synapse. 2011; 65(10):1087-1098. [PubMed: 21590747]

Redrobe JP, Bull S, Plath N. Translational Aspects of the Novel Object Recognition Task in Rats Abstinent Following Sub-Sub-chronic treatment with Phencyclidine (PCP): Effects of Modafinil and Relevance to Cognitive Deficits in Schizophrenia. Front Psychiatry. 2010; 1:146. [PubMed: 21423454]

Reichel CM, Ramsey LA, Schwendt M, McGinty JF, See RE. Methamphetamine-induced changes in the object recognition memory circuit. Neuropharmacology. 2012; 62(2):1119-1126. [PubMed: 22115899]

Reichel CM, Schwendt M, McGinty JF, Olive MF, See RE. Loss of object recognition memory produced by extended access to methamphetamine self-administration is reversed by positive allosteric modulation of metabotropic glutamate receptor 5. Neuropsychopharmacology. 2011; 36(4):782-792. [PubMed: 21150906]

Robinson TE, Berridge KC. The neural basis of drug craving: an incentive-sensitization theory of addiction. Brain Res Brain Res Rev. 1993; 18(3):247-291. [PubMed: 8401595]

Robinson TE, Kolb B. Structural plasticity associated with exposure to drugs of abuse. Neuropharmacology. 2004; 47(Suppl 1):33-46. [PubMed: 15464124] 
Sargolini F, Roullet P, Oliverio A, Mele A. Effects of intra-accumbens focal administrations of glutamate antagonists on object recognition memory in mice. Behav Brain Res. 2003; 138(2):153163. [PubMed: 12527446]

Schmaal L, Joos L, Koeleman M, Veltman DJ, van den Brink W, Goudriaan AE. Effects of modafinil on neural correlates of response inhibition in alcohol-dependent patients. Biol Psychiatry. 2013; 73(3):211-218. [PubMed: 22858150]

Schoenbaum G, Shaham Y. The role of orbitofrontal cortex in drug addiction: a review of preclinical studies. Biol Psychiatry. 2008; 63(3):256-262. [PubMed: 17719014]

Scoriels L, Jones PB, Sahakian BJ. Modafinil effects on cognition and emotion in schizophrenia and its neurochemical modulation in the brain. Neuropharmacology. 2013; 64:168-184. [PubMed: 22820555]

Scott JC, Woods SP, Matt GE, Meyer RA, Heaton RK, Atkinson JH, Grant I. Neurocognitive effects of methamphetamine: a critical review and meta-analysis. Neuropsychol Rev. 2007; 17(3):275-297. [PubMed: 17694436]

Shearer J, Darke S, Rodgers C, Slade T, van Beek I, Lewis J, Brady D, McKetin R, Mattick RP, Wodak A. A double-blind, placebo-controlled trial of modafinil (200 mg/day) for methamphetamine dependence. Addiction. 2009; 104(2):224-233. [PubMed: 19149817]

Simon SL, Dean AC, Cordova X, Monterosso JR, London ED. Methamphetamine dependence and neuropsychological functioning: evaluating change during early abstinence. J Stud Alcohol Drugs. 2010; 71(3):335-344. [PubMed: 20409426]

Soeiro Ada C, Moreira KD, Abrahao KP, Quadros IM, Oliveira MG. Individual differences are critical in determining modafinil-induced behavioral sensitization and cross-sensitization with methamphetamine in mice. Behav Brain Res. 2012; 233(2):367-374. [PubMed: 22652394]

Tritsch NX, Sabatini BL. Dopaminergic modulation of synaptic transmission in cortex and striatum. Neuron. 2012; 76(1):33-50. [PubMed: 23040805]

Urbano FJ, Leznik E, Llinás RR. Modafinil enhances thalamocortical activity by increasing neuronal electrotonic coupling. Proc Natl Acad Sci U S A. 2007; 104(30):12554-12559. [PubMed: 17640897]

Valjent E, Corvol JC, Pages C, Besson MJ, Maldonado R, Caboche J. Involvement of the extracellular signal-regulated kinase cascade for cocaine-rewarding properties. J Neurosci. 2000; 20(23):87018709. [PubMed: 11102476]

Valjent E, Pagès C, Hervé D, Girault JA, Caboche J. Addictive and non-addictive drugs induce distinct and specific patterns of ERK activation in mouse brain. Eur J Neurosci. 2004; 19(7):1826-1836. [PubMed: 15078556]

Vocci FJ, Appel NM. Approaches to the development of medications for the treatment of methamphetamine dependence. Addiction. 2007; 102(Suppl 1):96-106. [PubMed: 17493058]

Volkow ND, Chang L, Wang GJ, Fowler JS, Franceschi D, Sedler M, et al. Effects of modafinil on dopamine and dopamine transporters in the male human brain: clinical implications. JAMA: the Journal of the American Medical Association. 2009; 301(11):1148-1154. [PubMed: 19293415]

Young JW, Geyer MA. Action of modafinil-increased motivation via the dopamine transporter inhibition and D1 receptors? Biol Psychiatry. 2010; 67(8):784-787. [PubMed: 20132929]

Young JW, Kooistra K, Geyer MA. Dopamine receptor mediation of the exploratory/hyperactivity effects of modafinil. Neuropsychopharmacology. 2011; 36(7):1385-1396. [PubMed: 21412225]

Zack M, Poulos CX. Effects of the atypical stimulant modafinil on a brief gambling episode in pathological gamblers with high vs. low impulsivity. J Psychopharmacol. 2009; 23(6):660-671. [PubMed: 18583430]

Zanassi P, Paolillo M, Feliciello A, Avvedimento EV, Gallo V, Schinelli S. cAMP-dependent protein kinase induces cAMP-response element-binding protein phosphorylation via an intracellular calcium release/ERK-dependent pathway in striatal neurons. J Biol Chem. 2001; 276(15):1148711495. [PubMed: 11139572]

Zhai H, Li Y, Wang X, Lu L. Drug-induced alterations in the extracellular signal-regulated kinase (ERK) signalling pathway: implications for reinforcement and reinstatement. Cell Mol Neurobiol. 2008; 28(2):157-172. [PubMed: 18041576] 


\section{Highlights}

- $\quad$ Methamphetamine produces recognition memory deficits and failures in cortical ERK signaling.

- $\quad$ Acute modafinil administration improved methamphetamine-induced memory deficits.

- $\quad$ Modafinil restored ERK signaling in medial prefrontal cortex induced by novelty.

- We report modafinil protective properties against methamphetamine harmful effects. 

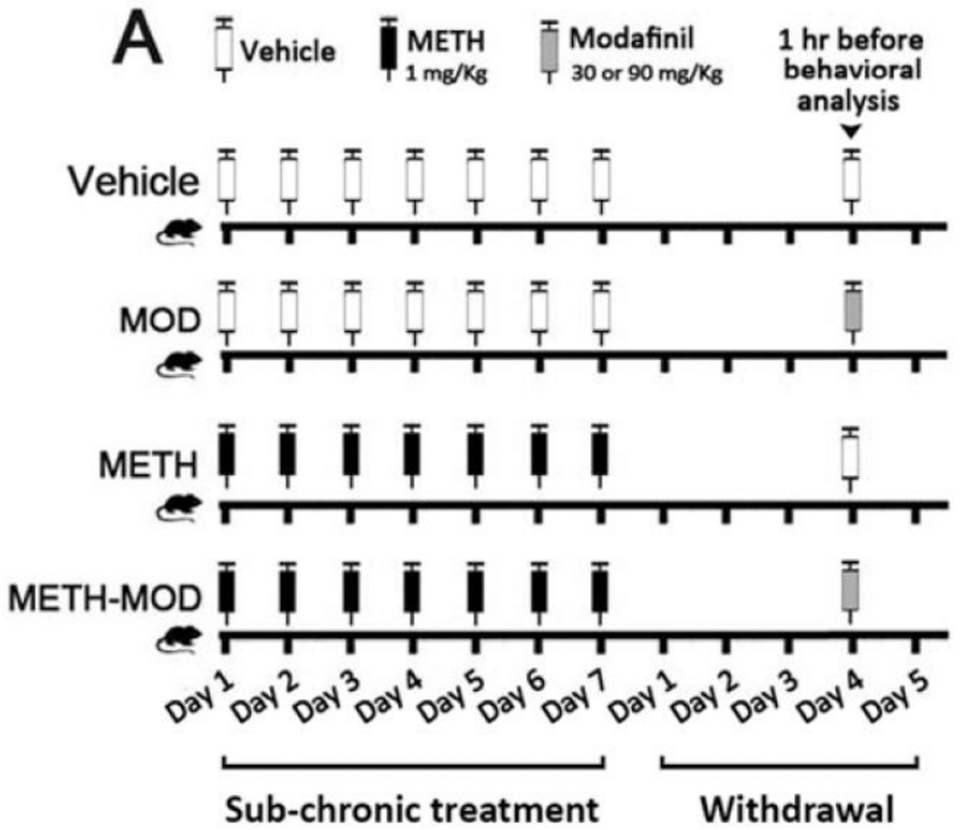

B METH withdrawal

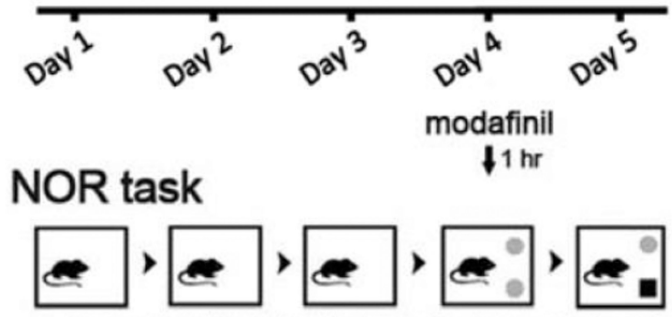

Open field habituation

Training Retention

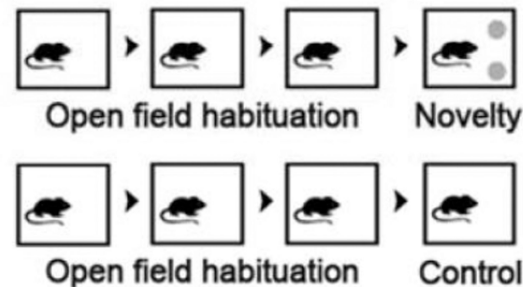

Figure 1. Schematic representations of the experimental treatments and behavioral analysis A) Male C57BL/6 mice were subjected to sub-chronic treatment with saline or METH 1 $\mathrm{mg} / \mathrm{Kg}$, sc, once a day for 7 consecutive days. On day 4 after sub-chronic treatment, mice received vehicle or MOD 90 or $30 \mathrm{mg} / \mathrm{Kg}$, ip, $1 \mathrm{hr}$ before behavioral analysis. B) METH withdrawal mice were habituated to the object recognition arena 5 min a day for 3 consecutive days. On withdrawal day 4, mice performed the Novel Object Recognition (NOR) task or were evaluated for the Novelty effect. For the NOR task, mice performed a training session in which they were allowed to freely explore two equal objects for $10 \mathrm{~min}$, and 24 hrs later (day 5) performed a 5 min retention session, where one of the familiar objects was replaced by a novel object. To evaluate the Novelty effect, mice performed a 10 min Novelty session where they were allowed to explore two equal novel objects and euthanized immediately. Control mice were placed in the arena in the absence of objects and the same procedure was performed. 

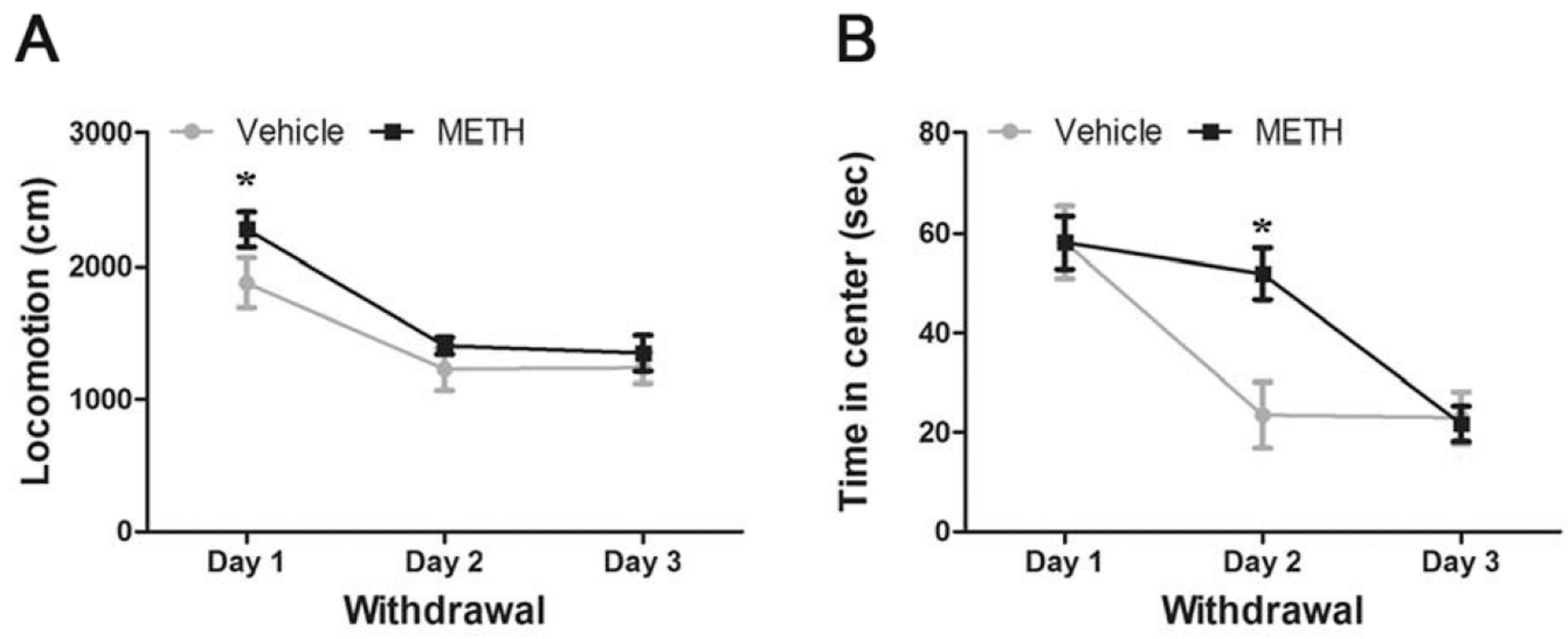

Figure 2. Effect of chronic METH withdrawal on exploratory activity

Mice were treated with vehicle or METH ( $1 \mathrm{mg} / \mathrm{Kg}$, sc, once a day for 7 days), and on withdrawal were placed in an open-top arena in a 5 min habituation session for 3 consecutive days. A) Locomotion, *: Day 1 different from Day 2 and Day 3 (p<0.05). B) Time in center, *: vehicle different from METH in Day 2. Exploratory activity during METH withdrawal was evaluated using Ethovision XT 7.0 tracking software (Noldus, Leesburg, Virginia). Repeated measures two-way ANOVA - Bonferroni. Values indicate mean \pm SEM $(\mathrm{N}=8-9)$, 
Modafinil 30 mg/Kg
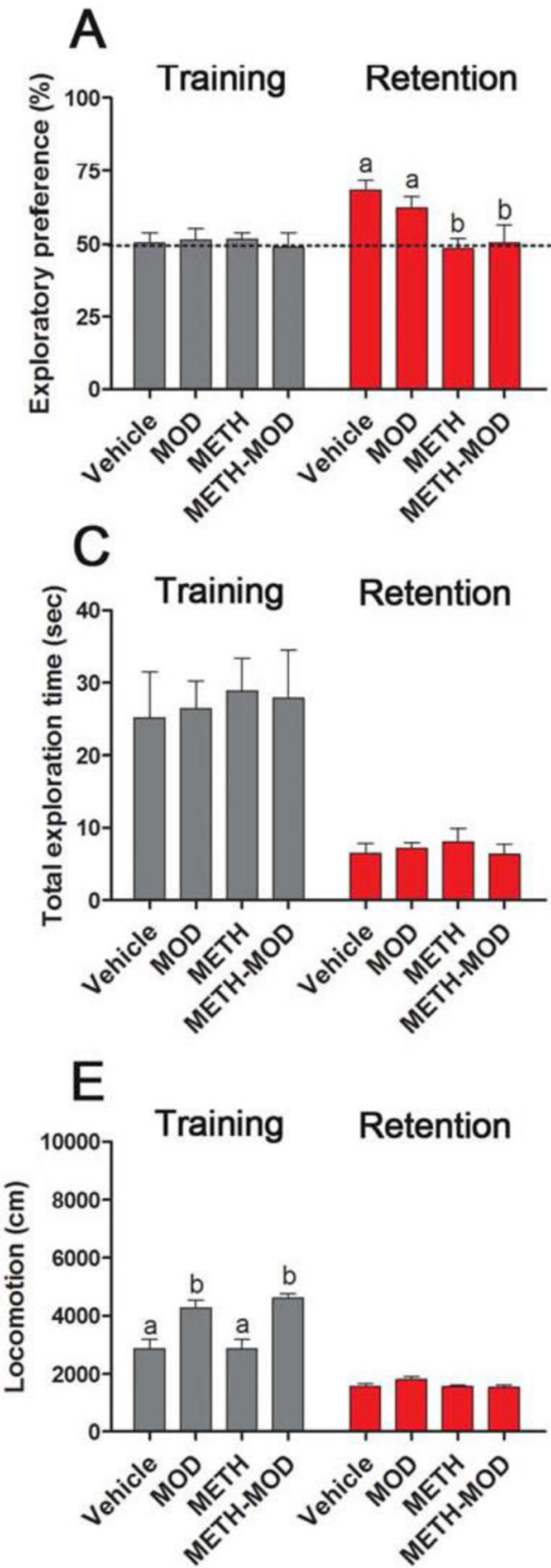

Modafinil $90 \mathrm{mg} / \mathrm{Kg}$
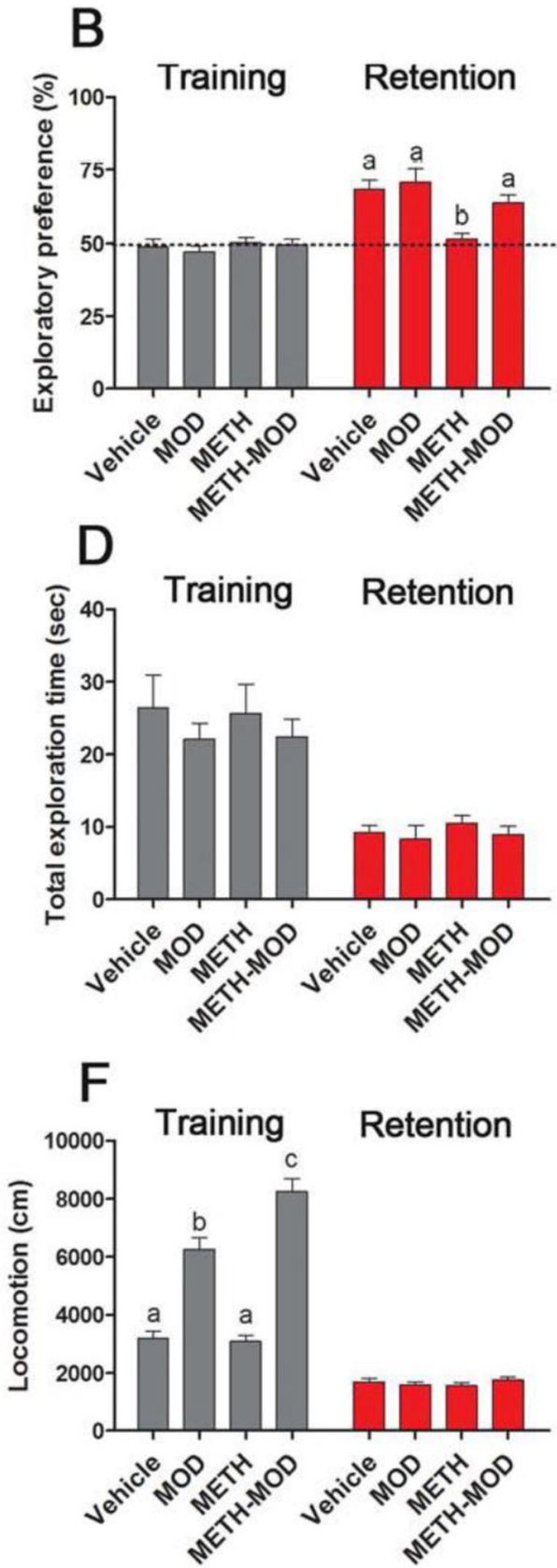

Figure 3. Effect of MOD on METH-induced cognitive impairment in a Novel Object Recognition task

A and B) Exploratory preference in training and retention sessions of chronic vehicle- and METH-treated mice, injected on withdrawal day 4 with vehicle or MOD 90 and $30 \mathrm{mg} / \mathrm{Kg}$, respectively; the dotted line at 50\% indicates equal preference for both familiar and novel object, indicative of visual memory impairment. MOD $90 \mathrm{mg} / \mathrm{Kg}$ retention session: ANOVA - Bonferroni. MOD $30 \mathrm{mg} / \mathrm{Kg}$ retention session: Kruskal Wallis ANOVA on ranks. C and D) Total exploration time in training and retention sessions of chronic vehicle- and METHtreated mice, injected on withdrawal day 4 with vehicle or MOD 90 and $30 \mathrm{mg} / \mathrm{Kg}$, 
respectively. E and F) Locomotion in training and retention sessions of chronic vehicle- and METH-treated mice, injected on withdrawal day 4 with vehicle or MOD 90 and $30 \mathrm{mg} / \mathrm{Kg}$, respectively. Time spent exploring objects and locomotion was analyzed with Ethovision XT 7.0 (Leesburg, Virginia). ANOVA - Bonferroni. Values indicate mean \pm SEM ( $\mathrm{N}=12-22)$, different letters: $\mathrm{p}<0.05$. 

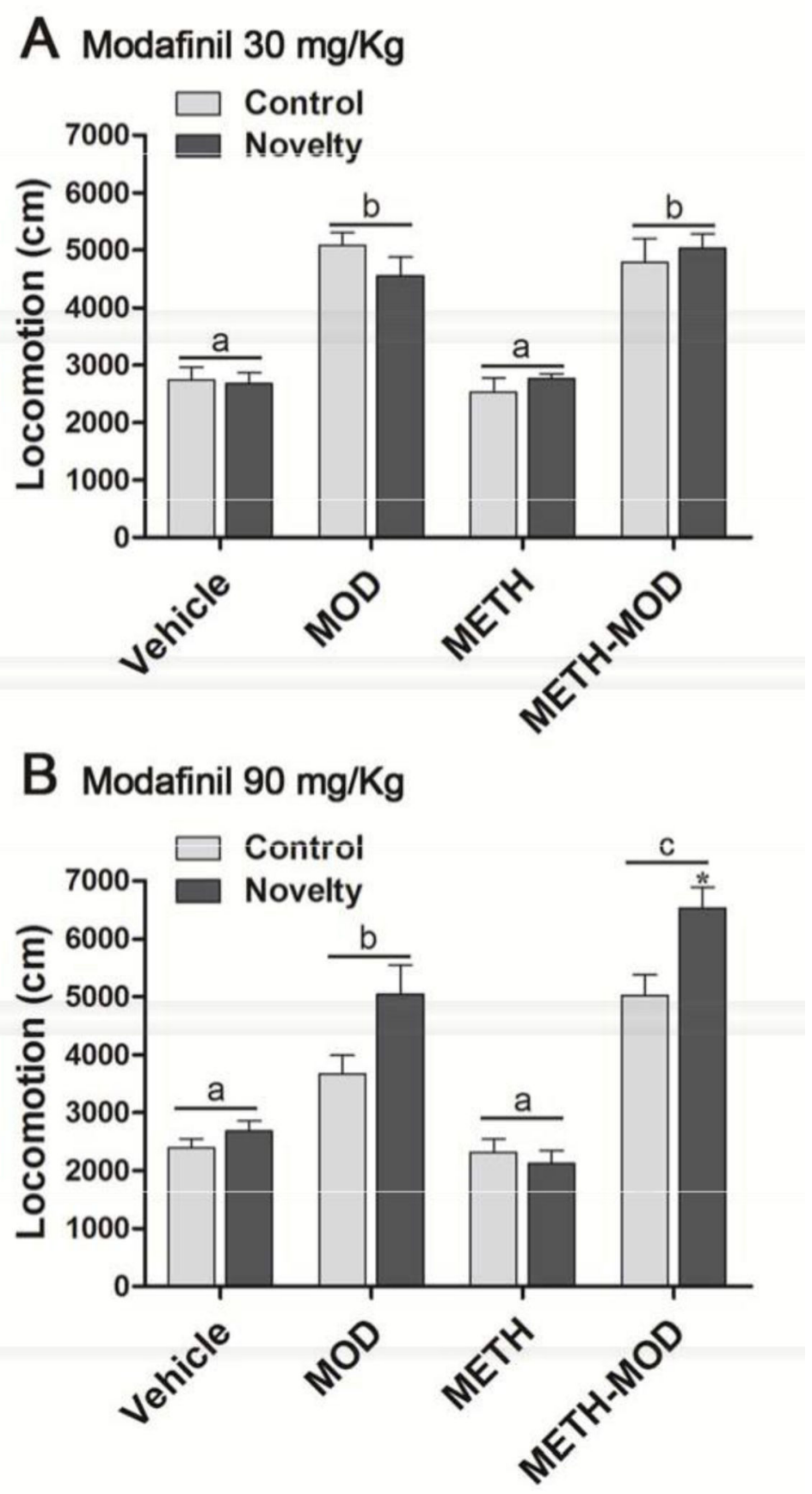

Figure 4. Effect of MOD on METH-induced changes in locomotion after novelty exposure On withdrawal day 4 after chronic vehicle or METH treatment $(1 \mathrm{mg} / \mathrm{Kg}$, sc, once a day for 7 days) mice received acute modafinil and $1 \mathrm{hr}$ later performed a $10 \mathrm{~min}$ Novelty session in which they were allowed to explore two equal novel objects and euthanized immediately. Control mice were placed in the arena in the absence of objects and the same procedure was performed. A) Modafinil $30 \mathrm{mg} / \mathrm{Kg}$, B) Modafinil $90 \mathrm{mg} / \mathrm{Kg}$. Locomotion was analyzed with Ethovision XT 7.0 (Leesburg, Virginia). Two way ANOVA - Bonferroni. Values 
indicate the mean \pm SEM $(\mathrm{N}=4-9)$, different letters: $\mathrm{p}<0.05$, *: different from METH-MOD control. 


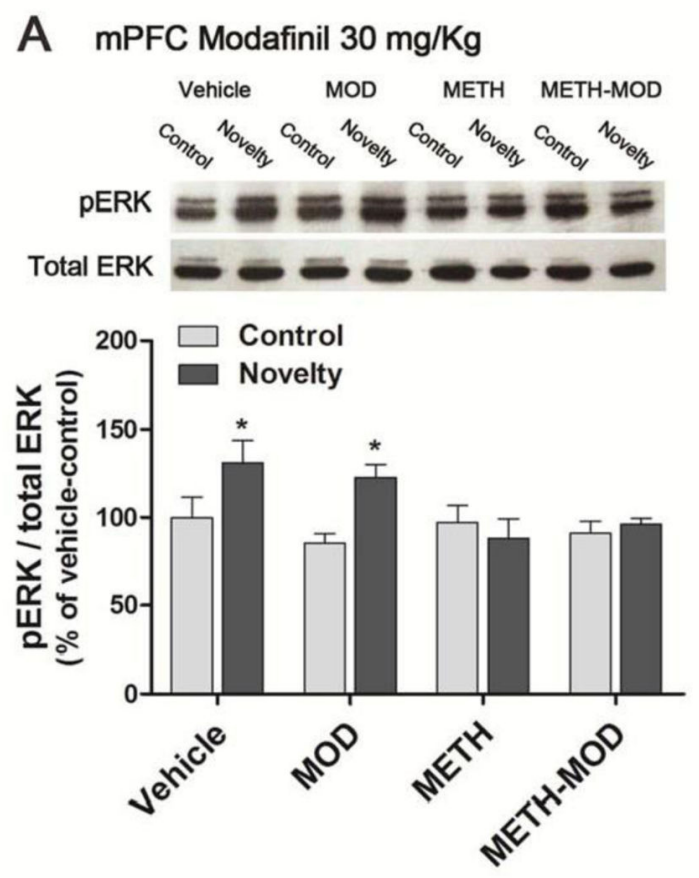

B $\mathrm{mPFC}$ Modafinil $90 \mathrm{mg} / \mathrm{Kg}$

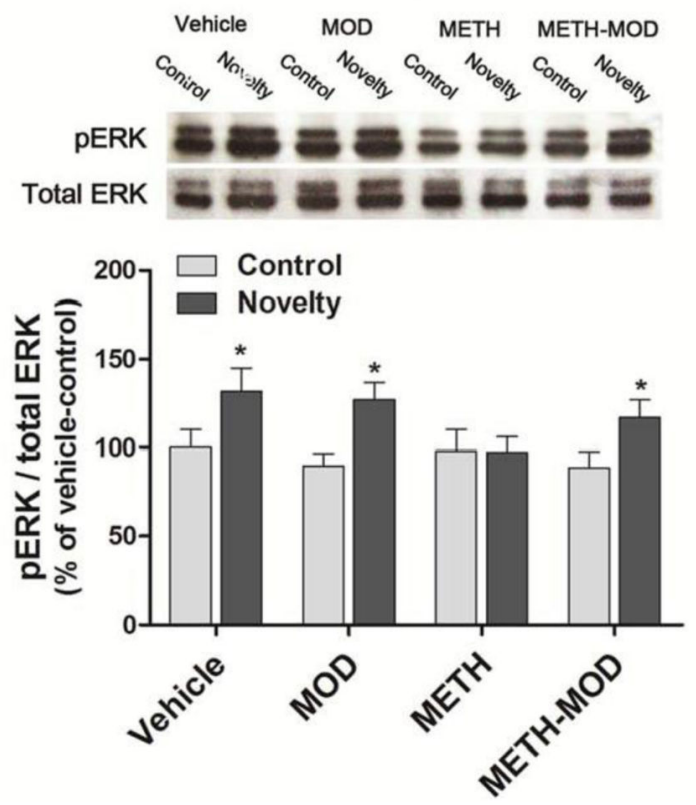

Figure 5. Effect of modafinil on METH-induced changes in ERK phosphorylation in the mPFC after novelty exposure

On withdrawal day 4 after chronic vehicle or METH treatment $(1 \mathrm{mg} / \mathrm{Kg}$, sc, once a day for 7 days) mice received acute MOD and $1 \mathrm{hr}$ later performed a $10 \mathrm{~min}$ novelty session, then euthanized immediately (novelty group). Control mice were placed in the arena in the absence of objects and the same procedure was performed (control group). A) Modafinil 30 $\mathrm{mg} / \mathrm{Kg}$. B) Modafinil $90 \mathrm{mg} / \mathrm{Kg}$. Two way ANOVA followed by planned contrasts between control and novelty within each treatment. Values indicate the mean \pm SEM (N=4-9), *: significantly different from control of the respective treatment. 
A Hippocampus Modafinil $90 \mathrm{mg} / \mathrm{Kg}$

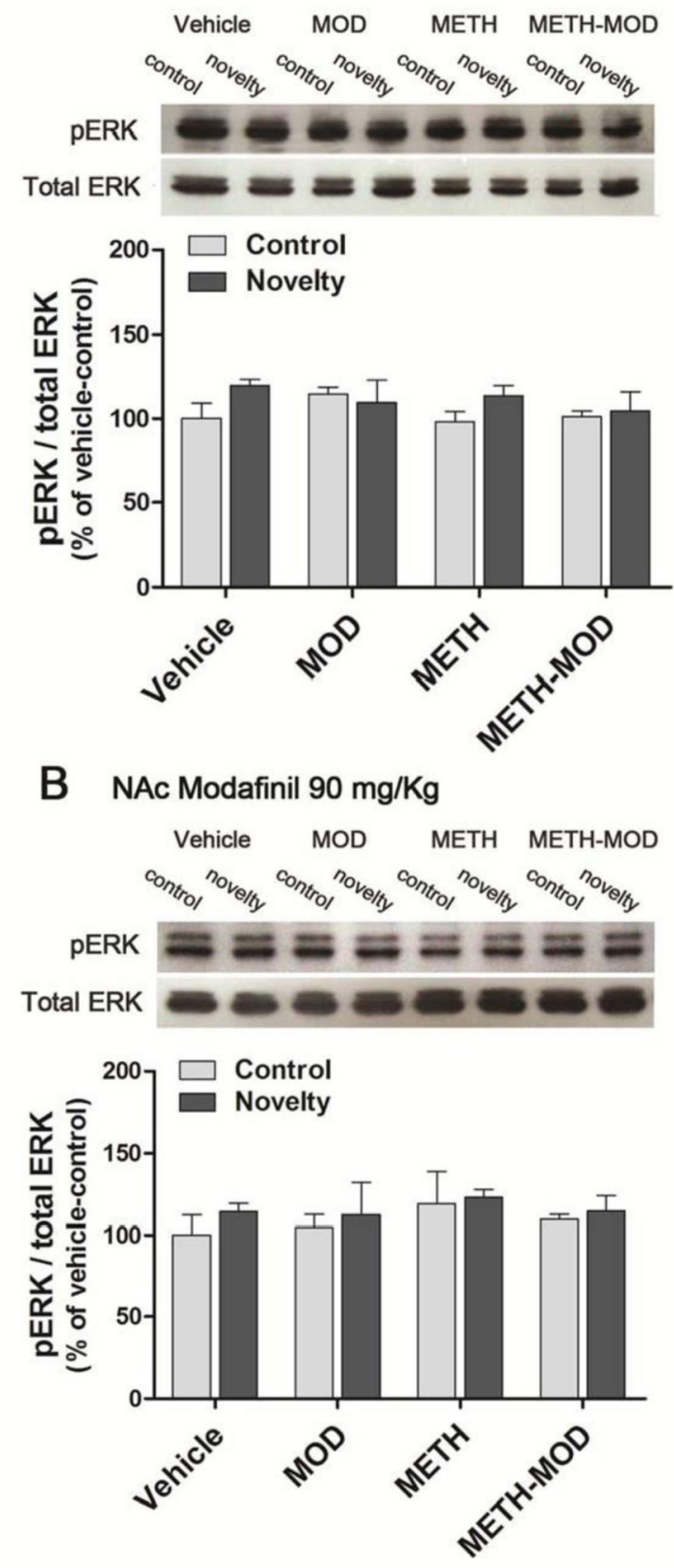

Figure 6. Effect of MOD on METH-induced changes in ERK phosphorylation in the hippocampus and nucleus accumbens (NAc) after novelty exposure

On withdrawal day 4 after chronic vehicle or METH treatment $(1 \mathrm{mg} / \mathrm{Kg}$, sc, once a day for 7 days) mice received acute modafinil $90 \mathrm{mg} / \mathrm{Kg}$ and $1 \mathrm{hr}$ later performed a 10 min novelty session, then were euthanized immediately (novelty group). Control mice were placed in the arena in the absence of objects and the same procedure was performed (control group). A) Hippocampus, B) Nucleus accumbens (NAc). Two way ANOVA. Values indicate the mean \pm $\operatorname{SEM}(\mathrm{N}=3-5)$. 